\section{Data on Atmospheric Research Aircraft Now Available From NCAR Computer by Remote Terminal}

\author{
Byron B. Phillips and R. B. Friesen, National Center \\ for Atmospheric Research, P.O. Box 3000, Boulder, CO \\ 80307
}

Atmospheric scientists with appropriate terminals can now easily telephone a data bank at the National Center for Atmospheric Research (NCAR) that summarizes key characteristics of 40 aircraft available for research. The data bank culminates an effort to ensure better, fuller use of the federal and academic research fleets. Over a year ago, a Working Group for Coordination of Research Aircraft (WGCRA) was formed by the Subcommittee for Atmospheric Research, Committee on Atmosphere and Oceans, to coordinate information on the use and availability of these aircraft. The WGCRA determined that the most immediate means of providing for the coordination was to establish a data summary of all research aircraft, listing their respective flight and instrumentation capabilities and conditions of availability. Clearly, there was a need for such information to be widely disseminated routinely to potential users in universities, government laboratories, and elsewhere, to insure that costly aircraft research facilities are made available to the scientific community on the broadest possible basis.

Consequently, a summary of data on public and private research aircraft has been assembled and stored at the NCAR computing center for access by potential users via phone lines from terminals at their home organizations. The NCAR center is presently equipped to distribute information in this way and routinely serves the current 53 member universities of UCAR. Use of the readily accessible aircraft data summaries will quickly inform potential users of what aircraft are capable of supporting and are available for specific programs, and should help insure that, as a community, we make fullest and best use of our research aircraft facilities. The information on university and government owned aircraft is extensive, including aircraft type and performance, person to contact, instrumentation and research provisions, and scheduled usage and availability. A much abbreviated summary of the same type of information is given for private aircraft routinely instrumented and available for research use.

Presently a total of 40 public and private aircraft are included (see Table 1). They range from a helicopter to fourengine transport-type aircraft, and can support research in chemistry and oceanography, as well as meteorology. NCAR's Research Aviation Facility (RAF) has had responsibility for acquiring the data and developing the software for user ac-

(c) 1984 American Meteorological Society cess. There has been excellent cooperation from all managers and groups in providing the reference data. A routine for updating the data is being implemented to assure current information is available.

The interactive Research Aircraft Data Bank Program was designed to be easy to use and self-explanatory. The program and the data reside on the IBM 4341 computer maintained by the Scientific Computing Division. The IBM 4341 was selected for this project because of its extensive communications interfaces and its availability to the university and research community.

To use the data bank:

1) Get in contact with the NCAR IBM 4341 computer. Before dialing, check the table of hardware requirements for communicating with the IBM 4341 against the type of equipment you are using. Particularly, note the appropriate class for the kind of terminal you have. Note also, all computer responses must be entered within about $15 \mathrm{sec}$ of the computer's prompt. If this is not done, the computer may disconnect the user, requiring him to initiate a connection again.

2) When you are ready, dial either (303)494-0490 or (303)494-0472. Listen for a high-pitched tone, then initiate a connection from your phone to your modem. After you press the [RETURN] key repeatedly for a few seconds, the "Enter class" prompt will appear. Then, depending on your terminal type (see Table 2 for details), enter the appropriate class type and press [RETURN]. (Following this, only limited mention of pressing the [RETURN] key after typing a line will be made, as it should always be done.)

3) If you have one of the terminals listed, you can use either class "I" or class " $E$ ", but class "I" is faster. Use class " $E$ " only if "I" is busy. Follow the instructions in the paragraph immediately below corresponding to the class "I" or "E". If you do not have one of the terminals listed, you must use class " 110 " and follow the instructions in the second section below.

For Class "I" or "E" Users Only (This is the recommended mode, but you must have one of the terminals specified in Table 2.

After you enter class "I" or "E", the computer will ask for your terminal type. Enter the name of the terminal you are using. If you followed the instructions correctly, you should now be in communication with the IBM 4341. The VM/370 logo should appear. Press [RETURN] once and you should see "CP READ" in the lower right-hand corner of your terminal screen. After this, enter the line:

\section{"L ADB WGCRA"}

and you will eventually receive the "NCAR/CMS ..." prompt. (If you receive the message "ADB ALREADY LOGGED ON ON GRAFF xxxx", it means you must wait until the user currently using the data bank is finished.) At this point, press [RETURN]. After a minute or so, you will 
TABLE 1. Aircraft listed in the WGCRA data bank.

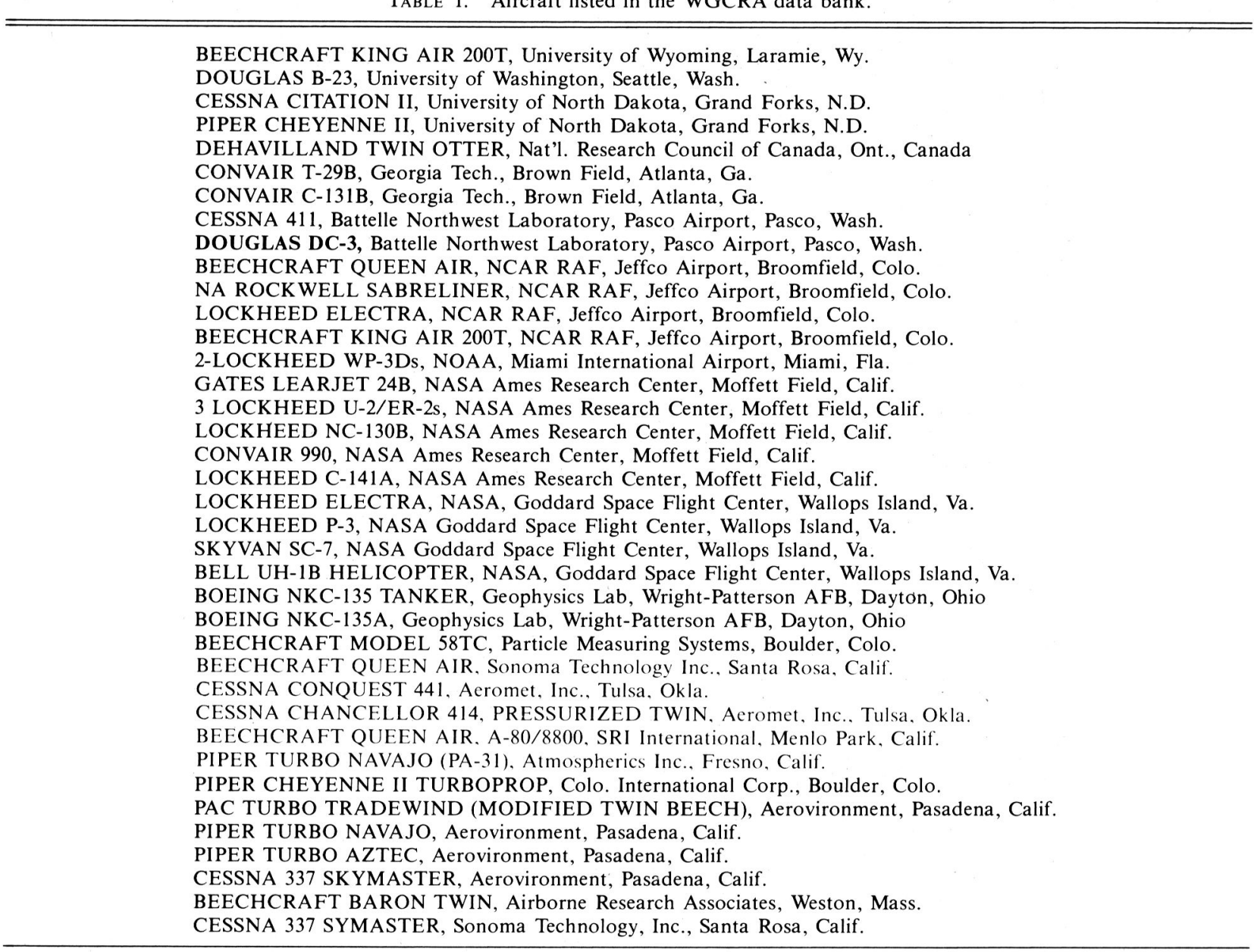

TABLE 2. Hardware requirements for communication with the IBM 4341 via telephone link.

Modems (300 or 1200 BAUD): BELL 103, BELL 212, VADIC 34xx.

Terminals and Their "Class Types"

1) Use class "I" for ADM3A, ADM5 (LEAR SIEGLER); PE1 100 FOX (PERKIN ELMER); VT100 (DEC); HP2648A (HEWLETT PACKARD); IBM3101, IBM31ALT (IBM). Type in the identifier ADM3A when logging on an ADM5 terminal. Use class "E" for PE1100 FOX; PE1200 OWL (PERKIN-ELMER); ADM3A, ADM5 (LEAR SIEGLER); VT100 (DEC); HP2648A (HEWLETT PACKARD); IQ 120 (SOROC).

Requires: Asynchronous data transfer, even parity, seven data bits, full duplex, one stop bit.

2) Use Class " 110 " for virtually any other ASCII terminal. Requires: Asynchronous data transfer, even parity, seven data bits, half duplex, one stop bit.

see the ". .. WGCRA DATA BANK ..." heading at the top of your screen. You are now ready to use the WGCRA Data Bank Program.

For Class "110" Users Only (Use this mode only if you do not have one of the terminals specified under Class "I" or "E"):

After entering class " 110 ", you should receive the "class 110 start" message. Press [RETURN] and the following prompt should appear: "ENTER "O" FOR NCAR IO, ENTER "A" FOR NCAR IA". At this point, press the letter [O] key. The "VM/370 ONLINE" message will be displayed; after receiv- ing it, press the [RETURN] key. The class 110 prompting character "." will now appear, meaning that the computer is expecting input. Type in the line "L ADB WGCRA" and you will eventually receive the "NCAR/CMS . . " prompt. (If you receive the message "ADB ALREADY LOGGED ON ON GRAF xxxx", it means you must wait until the user currently using the data bank is finished.) At this point, press [RETURN]. After a minute or so, you will see the “. . WGCRA DATA BANK ..." heading. You are now ready to use the WGCRA Data Bank Program. NOTE: From now on, when you receive the "." at the beginning of a 
line, the computer is expecting input. ONLY ENTER DATA AFTER YOU HAVE RECEIVED THE “.” PROMPT!

Please note that you must read all of the instructions from the program carefully. These are the key to successfully obtaining the data you want. Telephone line "noise" may appear as meaningless random characters on screen. Try redialing to obtain another line or call the number below for help.

Hard-copy printouts of aircraft data can be obtained via the NCAR remote job entry or through regular mail service as requested. For more information on using this program or to obtain help with problems, call Mike Daniels, RAF,
NCAR, at (303)497-1037. For general information, call the RAF Manager at (303)497-1032.

Acknowledgments. The authors are indebted to two fellow workers at the Research Aviation Facility-Peggy Taylor, who was instrumental in contacting the other aircraft groups and assembling the information, and Mike Daniels, who has written the software for user access to the NCAR IBM 4341, as well as entered the data. We also thank the various aircraft facilities for their cooperation and responsiveness, and recognize C. Downie, of the National Science Foundation, Chairman of the WGCRA for his leadership and support.

\section{announcements'}

\section{Meteorological news sought for national TV series}

A weekly science-news television report, How About..., is accepting story suggestions, especially meteorolgoical features, for its sixth season. The 80-second spots, hosted by Don Herbert, better known as "Mr. Wizard," are featured during news and informational programs broadcast on 138 stations across the country. Writers from public information offices at universities, corporations, government agencies, and research centers, as well as individual scientists, are encouraged to submit material.

Submitted stories must have source-provided film, videotape, or still photos available; the source and key scientists receive credit on the air. For more information, contact Mr. Wizard Studio, 132 Stagecoach Road, Canoga Park, CA 91307 (tel.: Head writer Joe Walders, 805-947-7583).

\section{Hurricane-like storms pose threat in Arctic}

The National Oceanic and Atmospheric Administration (NOAA) has documented, for the first time, the existence of arctic cyclones, fast-moving storms with hurricane-force winds and $16 \mathrm{~m}$ waves. In a six-week airborne study over the Norwegian Sea, NOAA established that the rotation motion of the storms can create circular surface winds strong enough to threaten oil rigs and capsize small vessels, and cause dangerous superstructure icing on ships.

Melvin Shapiro, senior meteorologist from NOAA's Environmental Research Laboratories in Boulder, Colo., said extensive data on storm structure and behavior, and sea state conditions, were gained on flights aboard a NOAA research plane from Iceland and Norway, at altitudes ranging from .3 to $8 \mathrm{~km}$.

The information collected over the Norwegian Sea in January and February of this year is pertinent to the Bering Sea and North Pacific Ocean off Alaska, and the northwest United States, according to project director Leonard Fedor. The study is expected to lead to better understanding and forecasting of storm development and movement from the Arctic Circle to populated areas.

'Notice of registration deadlines for meetings, workshops, and seminars, deadlines for submittal of abstracts or papers to be presented at meetings, and deadlines for grants, proposals, awards, nominations, and fellowships must be received at least three months before deadline dates.-News Ed.

\section{National Technology Medal nominations open}

Nominations are being accepted through 31 July 1984 for the second round of the National Technology Medals. The medals are awarded periodically by the President to recognize individuals and companies for "outstanding contributions to improving the wellbeing of the United States through the promotion of technology or technological manpower."

Nominations opened 1 May, and the awards will be presented next year. Instructions and nomination forms are available from Philip Goodman, Executive Director, National Technology Medal Nomination Evaluation Committee, Room 4824, U.S. Department of Commerce, Washington, DC 20230.

\section{meetings of interest}

8-11 October 1984: The French Aerospace Remote Sensing Development Organization (Groupement pour le Développement de la Télédétection Aérospatiale (GDTA) is organizing an International Conference on Training for Remote Sensing Users, in Toulouse, France. The aim of the conference is to review the various training programs existing all over the world; to estimate the importance of educational needs; and to promote relationships between demanders and training suppliers. For more information contact GDTA Formation-Section "Colloques," 18, avenue Edouard-Belin, 31055 Toulouse Cédex, France.

23-25 October 1984: The Third Conference on Interactive Meteorological Processing (IMP) will be hosted by the Goddard Space Flight Center in Greenbelt, Md. The conference, which will be sponsored by the National Aeronautics and Space Administration, the National Oceanic and Atmospheric Administration, and the USAFRange Commanders Council, will cover state-of-the-art of IMP in government, military, universities, and in the private sector, both in the United States and abroad. Papers will be accepted on state-of-the-art IMP systems /functional hardware and software aspects|, proposed future systems, networking, and data base access (particularly weather central distribution of data and products). Titles and abstracts (less than 100 words) are due by 1 